\title{
Quasi-resonance effects observed in the 1994 Northridge earthquake, and others
}

\author{
Edward G. Fischer ${ }^{\mathrm{a}}$ and Thomas P. Fischer ${ }^{\mathrm{b}}$ \\ ${ }^{a}$ Fischer Consulting, 5525 Third Street, Verona, \\ PA 15147, USA \\ Tel.: +1 4127930224 \\ ${ }^{\mathrm{b}}$ Astro Nuclear/Dynamics, Inc., 811 Route 51 South, \\ Large, PA 15025, USA \\ Tel.: +1 412382 7173; Fax: +1 4123824927
}

Received 18 September 1995

Revised 26 June 1998

Sine-beat phenomena have been found in the 1994 Northridge earthquake records, and they are capable of producing time-history responses and damaging quasiresonance effects in structures. Linear, single DOF (degree of freedom) oscillators, in lieu of nonlinear, multiple DOF systems, have been found adequate to discuss the failures of tall circuit breakers during the 1971 San Fernando and the 1989 Loma Prieta quakes in California. The use of sinebeat excitation for seismic-shaking-table tests of equipment continues to be a conservative simulation of earthquakes.

Keywords: Northridge, earthquake, quasi-resonance, sinebeat, circuit breaker

\section{Introduction}

The Northridge earthquake on January 17, 1994 measured only 6.6 on the Richter scale; however, excessive horizontal and vertical accelerations of $1.82 \mathrm{~g}$ and $1.18 \mathrm{~g}$, respectively, were recorded at the Tarzana Station, about 4.3 miles south of the epicenter. The main event was considered to be a thrust mechanism at a depth of about 30 miles, wherein a series of jolts went hopscotching across a wide expanse of Los Angeles and Ventura counties.

The digitized and processed free-field records (acceleration time-histories) obtained from five CSMIP (California Strong-Motion Instrumentation Program) Stations were quickly made available to the public. However, the only record to be used as an illustration in this paper was obtained at the Santa Monica (City
Hall Grounds) Station, some 14.9 miles from the earthquake epicenter.

In addition to showing the acceleration time-histories, the corresponding "response-spectra" data were shown plotted on quadra-log paper. However, no mention was made of the underlying time-history-responses at each frequency, and here is where the authors were able to plot out important sine-beat response phenomenon.

The Northridge quake has been the first opportunity for the authors to analyze some digitized and processed free-field seismograms without justifying their applicability to specific equipment failures. A careful examination arouses attention because of their lowfrequency vibration content, sometimes showing approximate sine-beat effects. The frequency can be verified by a distinct g-level peak in the shock response spectrum, which is customarily provided [1].

The purpose of this paper is to supplement the descriptive seismic response plots with the underlying time-history responses at all possible equipment natural frequencies. The result has been the revelation of conceivable quasi-resonance response phenomena, something which is rarely mentioned in publications on earthquakes.

An interesting practical verification of sine-beat resonance appeared to occur during the 1970 Gediz quake and was described in the literature as follows: "The prime reason why a low value of ground acceleration caused such surprisingly heavy damage to modern reinforced concrete structures is concluded to be the resonance phenomenon arising from the natural period of the structures coinciding with the predominant period of the soil" [3].

\section{Seismic response plotted as an acceleration-time history}

The response spectrum was originally suggested to give a peak g-level indication of potential damaging effects of earthquakes on buildings. The peaks corre- 


\section{NORTHRIDGE - 2\% DAMPING - 90 DEG}

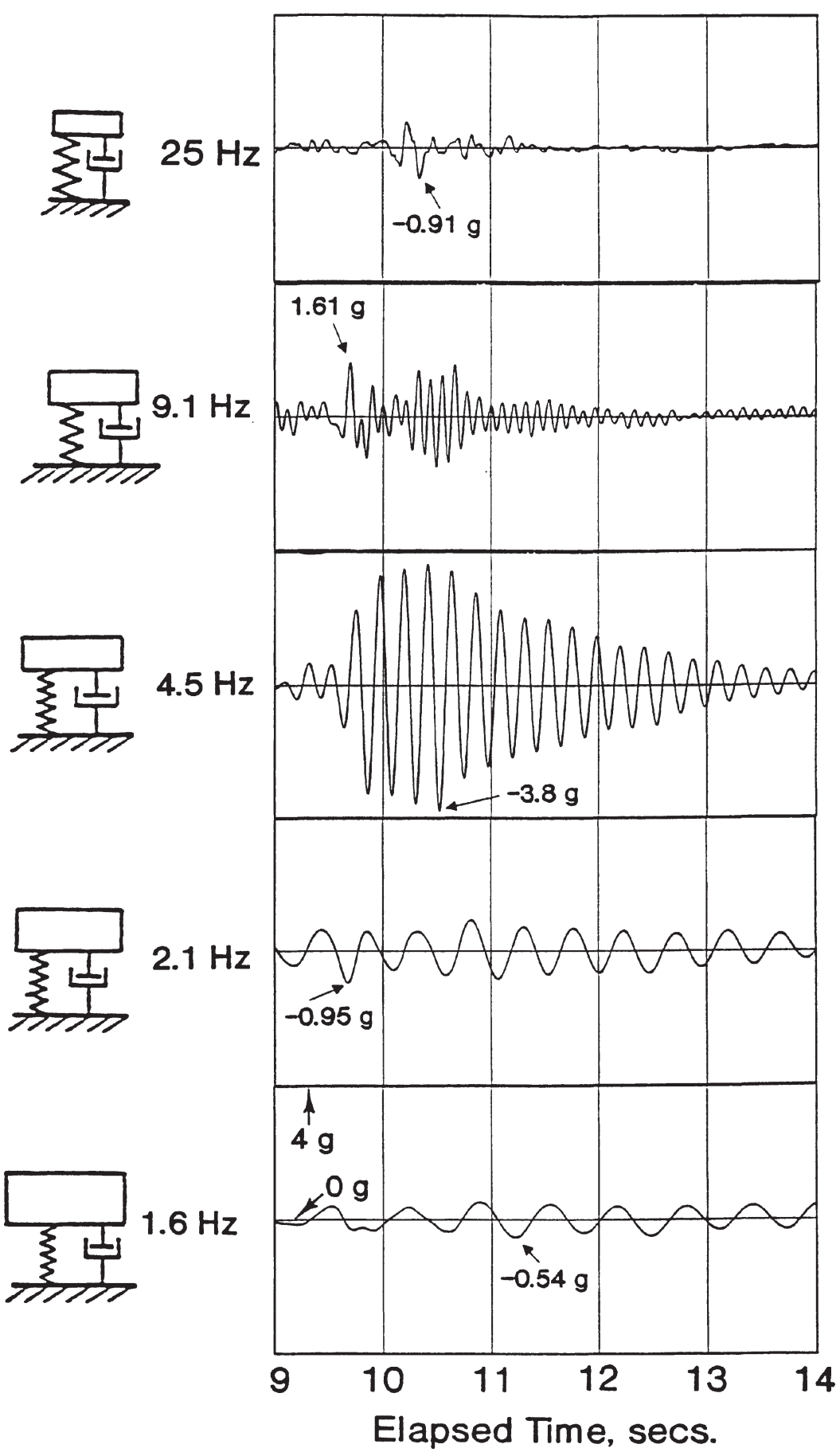

Fig. 1. Acceleration (g-level) time-history-responses at various frequencies and $2 \%$ damping at Santa Monica station to the 1994 Northridge earthquake. 


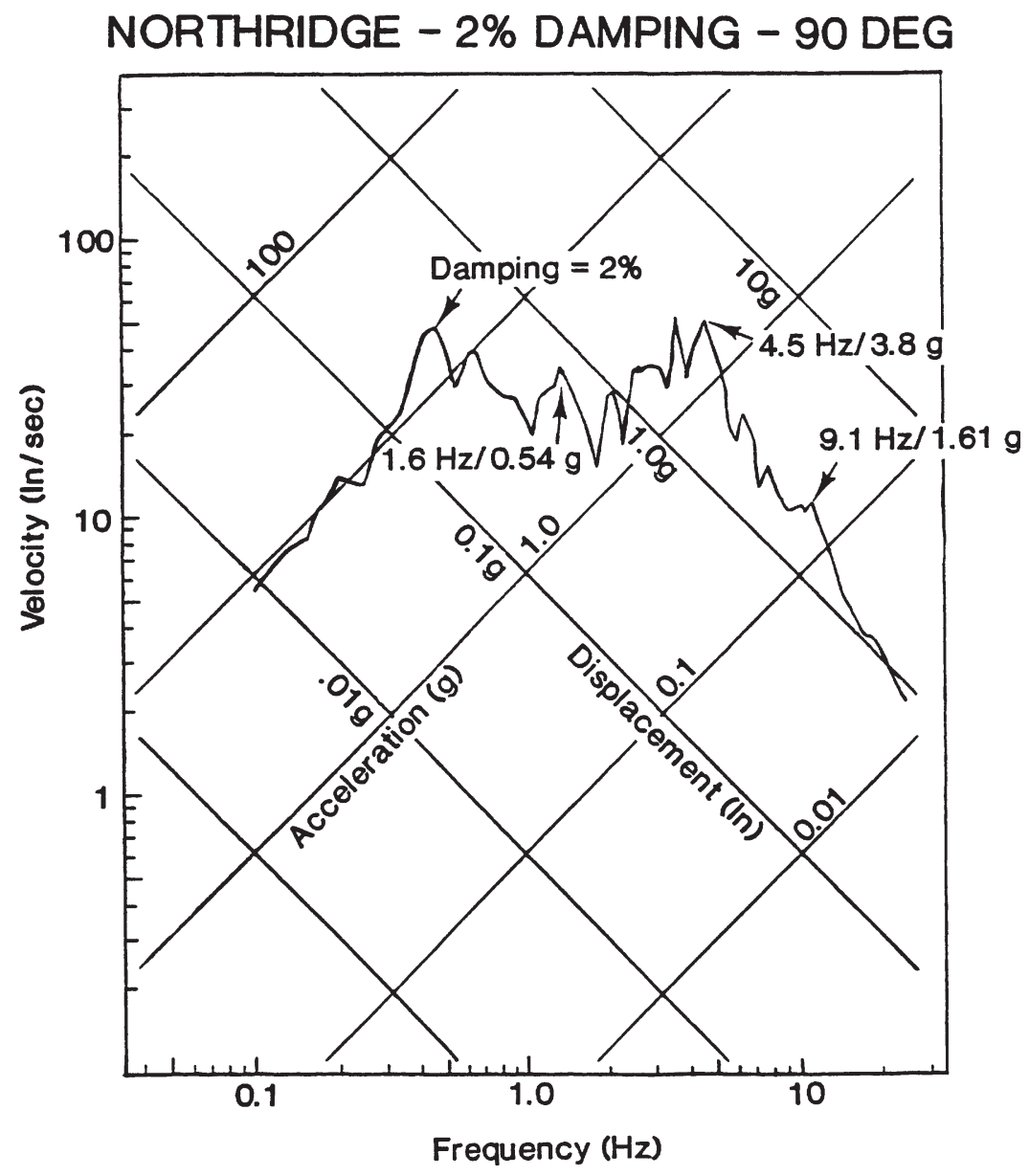

Fig. 2. Quadra-log plot for the response at 2\% damping at Santa Monica station during the 1994 Northridge earthquake.

spond to those for a series of linear, single DOF oscillators subjected to a seismic time-history acceleration applied to their base supports. However, the timehistory of the response is "lost", along with the number of damaging stress cycles at each natural frequency. Fortunately, this information can be retrieved from the original spectra program by extracting the response time-history plots at each chosen frequency, before the "maximizing" procedure takes place.

Figure 1 shows a composite picture of the Santa Monica time-history responses for several representative frequencies, and some of them show important acceleration buildup. Also, it is noted that the response of the $25 \mathrm{~Hz}$ simple oscillator corresponds closely to the original seismic recording at the Santa Monica Station. During the time interval from 9 to 14 seconds, wherein most of the peak g-level responses occur, it is evident that drastic motion starts at about 10 seconds.

As shown, the so-called sine-beat, quasi-resonance phenomenon at $4.5 \mathrm{~Hz}$ and $2 \%$ critical damping reaches a peak of $3.8 \mathrm{~g}$, and represents potential damage to a structure with the same natural frequency. Also, the time-response shows an important vibration "fatiguing effect". Figure 2 shows the usual composite, quadra$\log$ plot of the response spectra for all the frequencies, but only at the $2 \%$ damping value. It shows the corresponding peak g-levels from Fig. 1, but has "lost" the important number of damaging cycles of corresponding fatigue stress.

Similar quasi-resonance responses are found throughout the Northridge seismograms, which were obtained at different locations about the epicenter, but have different low-frequencies and occur at lower g-levels. In addition, similar phenomena have been found in the free-field recordings obtained for other recent earthquakes, as follows: Fig. 3, similar to Fig. 1, shows a composite picture of the responses at representative frequencies for the 1989 Loma Prieta quake at the Corralitos station. The response of the $25 \mathrm{~Hz}$ simple oscillator is approximately the original seismic recording. 


\section{CORRALITOS - 2\% DAMPING, CHN 2 - UP}

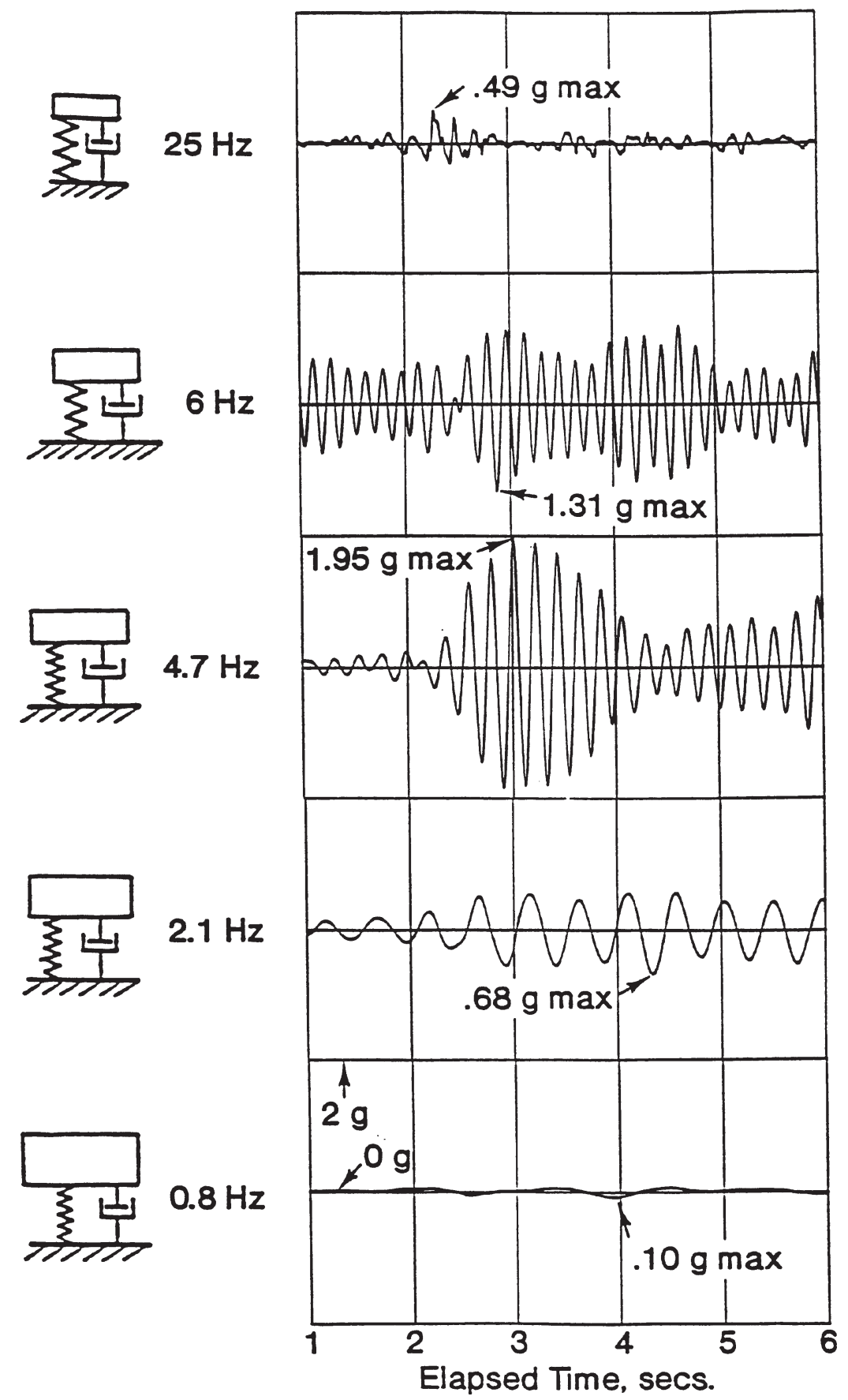

Fig. 3. Acceleration (g-level) time-history-response at Corralitos station during the 1989 Loma Prieta earthquake.

Figure 4 shows a time-history response for the 1991 Centre Hall quake, where the measuring site was located in the middle of Pennsylvania. Although considered only a minor seismic event at Penn State Univer- sity, it shows the characteristic sine-beat response resonance at $2.0 \mathrm{~Hz}$.

From a mechanical engineer's perspective, these departures from random ground motion can cause quasi- 
1991-Centre Hall Earthquake-2H, 2\%Damping

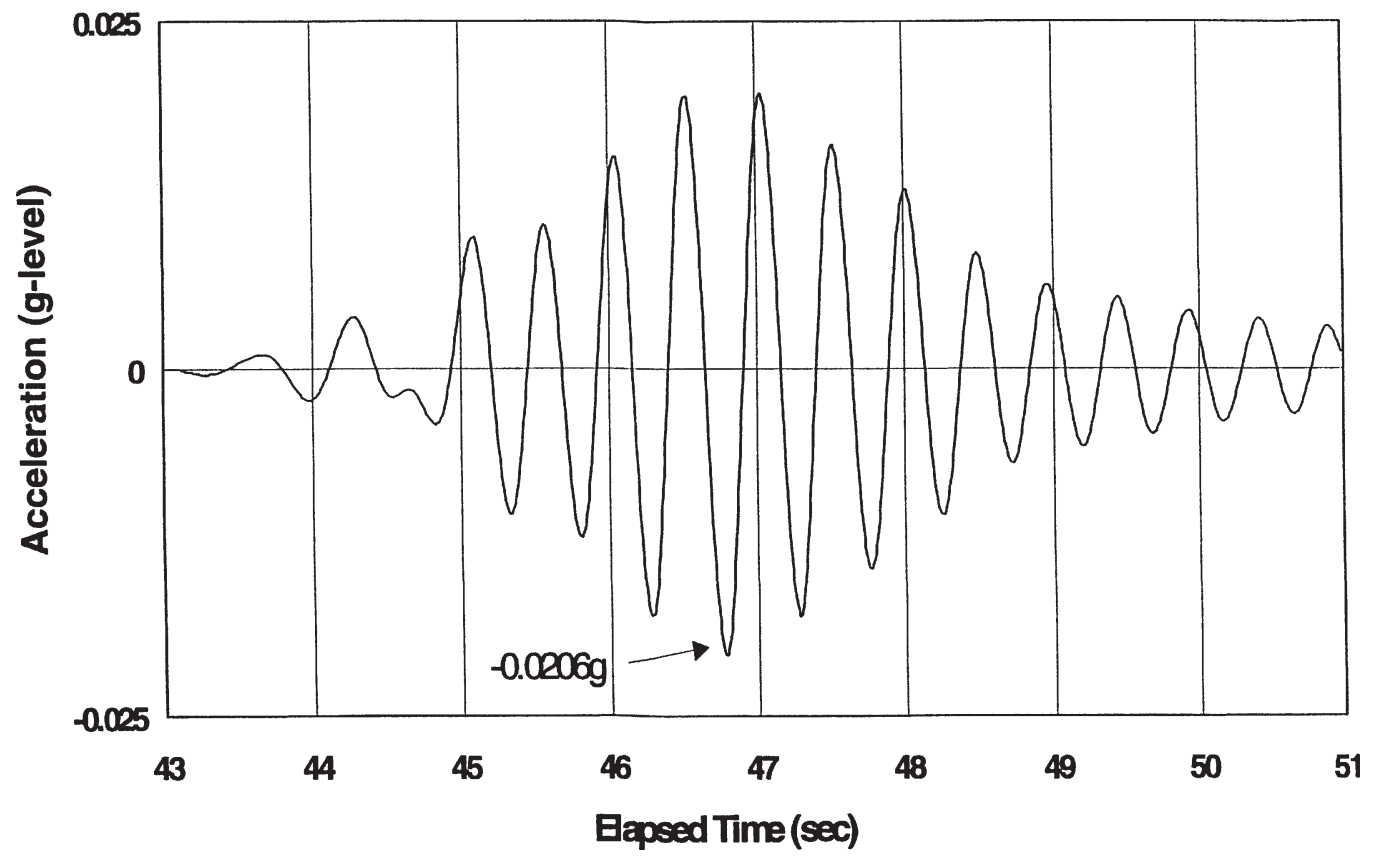

Fig. 4. Acceleration (g-level) time-history-response at Centre Hall station during the 1991 Centre Hall earthquake in Central Pennsylvania.

resonance magnifications at the natural frequency of a building or an electrical equipment structure. These phenomena occur in the frequency range from 1 to $25 \mathrm{~Hz}$, and it is axiomatic that adding damping to such systems can be used to limit vibration amplitude buildup. In anticipation of mechanical failures in the field, sine-beat testing was developed and incorporated as part of IEEE Std. 344 during the years 1971, 1975, and 1987. The subsequent vibration-table testing was considered very conservative since quasiresonance was made to occur at each natural frequency that could be found by test in the equipment structure.

\section{History of the development of sine-beat testing}

Starting with the oft-quoted 1940 El Centro quake, which was subsequently described as a series of four or five sequential tremors, the custom has been to design structures according to a broadband seismic response spectrum, where the peaks and valleys were intentionally "smoothed out". However, Rice (1944) at Bell Labs and Plunkett (1969) at the University of Minnesota have shown that random-type ground motion during transmission can respond as a "narrow-band, quasi-sinusoidal waveform with a slowly-varying amplitude". This would explain the low-frequency ampli- tude fluctuations first noticed in the Corralitos Station records for the 1989 Loma Prieta quake. It is of interest to note that this quake was often referred to as the "San Francisco" quake because of some resonant-type structural failures some 60 miles from the epicenter near Santa Cruz, namely: the Embarcadero buildings, the Bay Bridge and the Highway 101 viaduct.

Originally, the sine-beat excitation had to be inferred from the circuit breaker equipment response to the 1971 San Fernando quake at Sylmar, California and much later to the 1989 Loma Prieta quake at Moss Landing, California. In both examples it was evident that a resonant-type of vibration buildup caused the destruction of these identical $500 \mathrm{Kv}$ electrical circuit breakers, which were known to have natural frequencies at about $2.6 \mathrm{~Hz}$. Not only the peak g-level, but also the large number of stress cycles would have caused failure according to earlier seismic tests. (Sine-beat vibration testing was originally presented, orally, at the Riverside, CA meeting of the Seismological Society of America on March 25, 1971.)

The history of seismic proof-testing shows that with the introduction of 3-D shaking tables and random (earthquake) motion inputs, the equipment suppliers have found it to be an easier test to pass, because of fewer test runs being required. (Also, resonant-type failures do not occur.) The principle use has been 
to locate malfunction of sensitive electrical devices, wherein the safety-related equipment fails to perform its proper function. However, when low-frequencies are found by test of the structures, and strength and fatigue-resistance become important, then sine-beat excitation to produce quasi-resonance continues to be the preferred test. For example, the present IEEE subcommittee on Seismic Design of Substation Equipment (1996) recommends sine-beat rather than random motion excitation.

\section{Mathematical modelling}

When malfunction of sensitive devices is not involved, it becomes expedient to use computer-aided analysis for the design of aseismic equipment. The well-known finite element method using mathematical models of structures can be used to advantage. This method requires linear elements and superposition of responses. Hence, a multiple DOF system can be simplified in terms of equivalent single DOF systems. However, when nonlinear DOF systems must be analyzed, then time-history inputs are necessary and the model becomes more complicated. A more tedious, step-by-step solution becomes necessary. Unless the nonlinearities produce distinctly new response phenomena (i.e., relaxation oscillations, subharmonic resonance, et cetera) the authors do not recommend such an exhaustive treatment. Based upon experience, we have enough trouble solving the linear problems, without bringing up nonlinearities.

\section{Conclusions}

The present analysis of the 1994 Northridge quake records completes an investigation of possible quasiresonance in structures that started with some Westinghouse circuit breaker failures caused by the 1971 San Fernando quake at Sylmar, California. Quite a few years later, some similar failures caused by the 1989 Loma Prieta quake at Moss Landing, California have verified the results of the sine-beat shaking-table tests performed at the EERC (Earthquake Engineering Research Center) at Richmond, California in 1976. As could have been predicted, the ill-advised removal of the special damping devices installed at Mosside Landing gave assurance that quasi-resonance failures were inevitable [2].

Unfortunately, definitive seismic recordings at the sites of the circuit breaker failures, as well as stressfatigue measurements on the equipment, were either too much to expect if left to chance, or otherwise not made available. However, the seismic records obtained for the Northridge, Loma Prieta and Center Hall quakes indicate that sine-beat-excited, quasi-resonance response motion is a distinct possibility at quite a few frequencies in the 1 to $25 \mathrm{~Hz}$ range.

To mechanical engineers, these phenomena can be avoided by insisting upon more rigid structures, at least above a natural frequency of $10 \mathrm{~Hz}$. Otherwise, it might be practical to add special dampers to avoid destructive motion buildup. In general, there is a need for more microzonation studies to indicate local damage potential. The reader is left to imagine the various buildings, highway structures, electrical equipment, et cetera, that could be damaged if they happened to be "tuned" to an excitation frequency present in the earthquake.

\section{Acknowledgment}

The authors wish to express their appreciation to William P. Welch of Santa Cruz, California, for his timely reporting of the 1994 Northridge earthquake news accounts to Pittsburgh, Pennsylvania. Also, to Jason P. Smith for information on the 1991 Centre Hall earthquake and to Suzan C. Bissert-Fischer for her computer programing and typing of this paper.

\section{References}

[1] R. Darragh, T. Cao, C. Cramer, M. Huang and A. Shakal, Processed CSMIP strong-motion records from the Northridge, California earthquake of January 17, 1994, Rpt. No. OSMS 9406B, Office of Strong Motion Studies, Sacramento, CA, 1994, 95814-3531.

[2] E.G. Fischer and W.M. Daube, Combined analysis and test of earthquake resistant circuit breakers, Int. J. Earth. Eng. \& Str. Dyn. 4(3) (1976), 231-244.

[3] S.S. Tezcan and M. Ipek, Long distance effects of the 1970 Gediz, Turkey Quake, Int. J. Earth. Eng. \& Str. Dyn. 1 (1973), 203-215. 

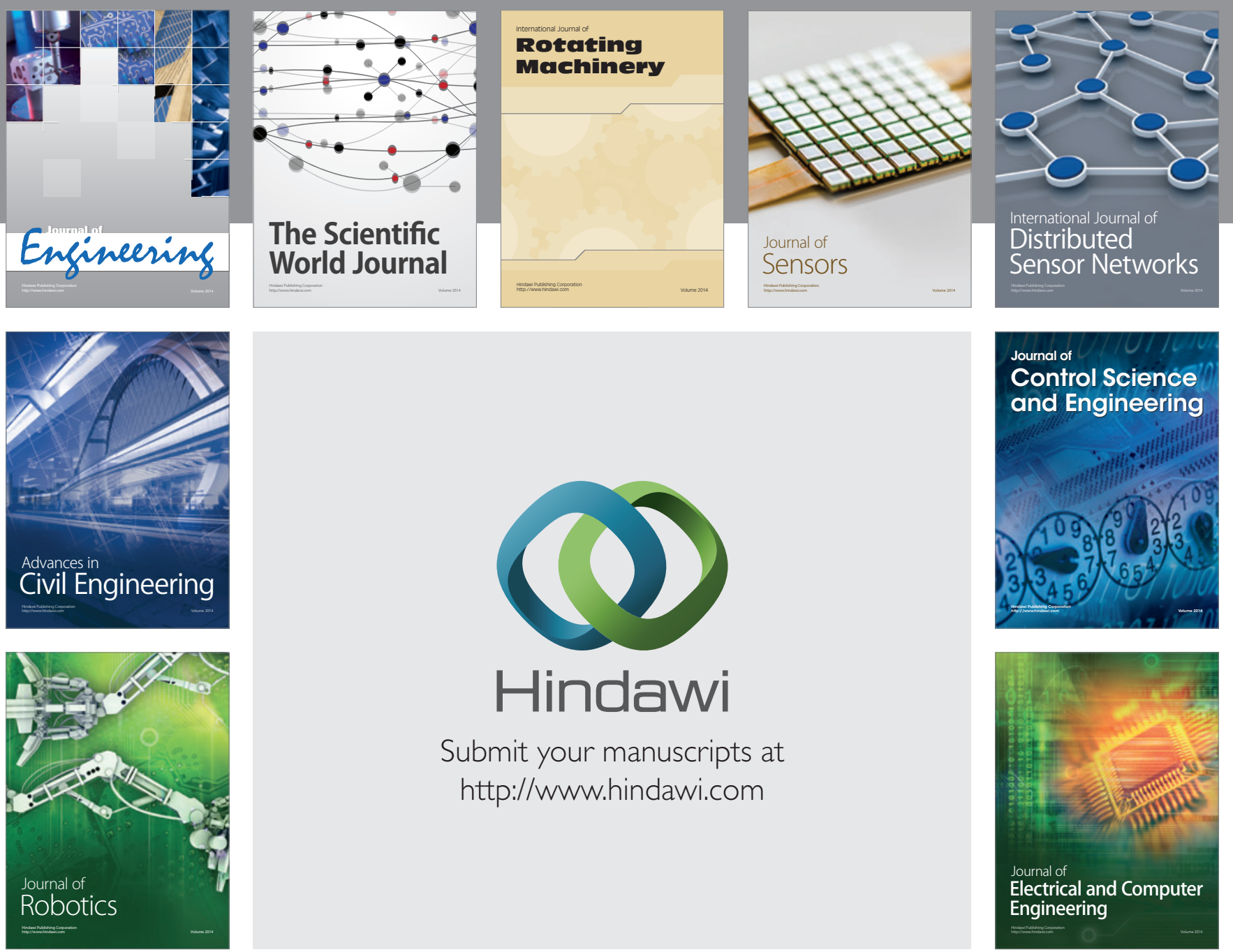

Submit your manuscripts at

http://www.hindawi.com
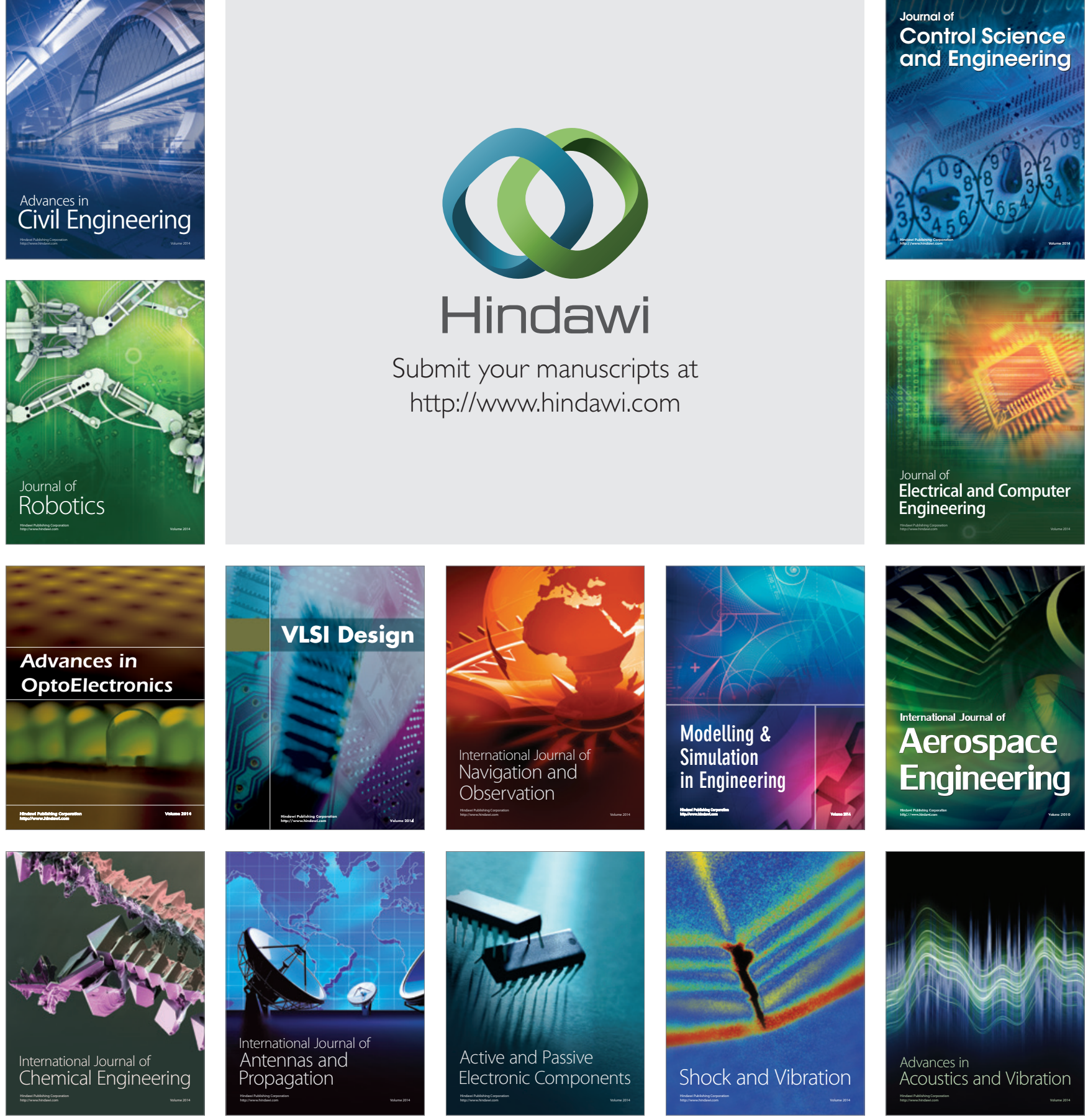